(C2004 IEEE. Personal use of this material is permitted. However, permission to reprint/republish this material for advertising or promotional purposes or for creating new collective works for resale or redistribution to servers or lists, or to reuse any copyrighted component of this work in other works must be obtained from the IEEE. 


\section{Model Design of Wind/PV/Fossil-Fuel Hybrid Systems}

\author{
Javier Lagunas \\ Renewable Energy Unit \\ Electrical Research Institute \\ Avenida Reforma 113, \\ Cuernavaca \\ Morelos, 62490, Mexico
}

\author{
Patricia Caratozzolo \\ Electronics Department \\ Cenidet \\ Interior Internado Palmira S/N, \\ Cuernavaca \\ Morelos, 62490, Mexico
}

\author{
César Ortega \\ Control and Instrumentation Unit \\ Electrical Research Institute \\ Avenida Reforma 113, \\ Cuernavaca \\ Morelos, 62490, Mexico
}

Raúl González

Renewable Energy Unit

Electrical Research Institute

Avenida Reforma 113,

Cuemavaca

Morelos, 62490, Mexico

\begin{abstract}
This paper presents the analysis and design of a mathematical model for a hybrid-power generation system consisting of a photovoltaic array, wind-turbines, a batterybank and a backup fossil-fuel generator. The static mathematical models of each element are validated by comparing them with field-data obtained in an experimental hybrid generation system installed in Pachuca, Mexico. Two different state-of-charge models were simulated and compared. The results are presented in this paper. The main purpose of this work is the devejopment of a fuzzy-supervisory-controller for small hybrid-systems.
\end{abstract}

\section{INTRODUCTION}

In Mexico, during the past few years, work has been done in the design and development of small scale hybrid-power generation systems. These systems are intended for isolated communities faraway from the power network. They provide energy for lightning and small production processes.

Recently, research groups in renewable energies and automatic control have joined efforts to incorporate intelligent-control algorithms into photovoltaic/wind/fossilfuel power generation systems. The main purpose of these works is the development of fuzzy-supervisory-controllers for small hybrid-systems. The main goals of the controller are: maximize the use of renewable-energy power sources, minimize the use of the fossil-fuel-generator, and minimize the cycling of the battery-bank.

This paper presents simulation models for each hybridpower system component, along with the results obtained from simulating the whole system.

\section{HYBRID SYSTEM CONFIGURATION}

Renewable-energy power systems are well defined. Most of them use wind-turbines and photovoltaic arrays (PV). Small hybrid systems also include an internal-combustion power generator that delivers the energy the renewable sources and the batteries cannot provide, given a particular load.

When the hybrid system generates more than the energy required by a particular load, the surplus energy has to be stored either in a battery bank, or in a bydrogen storage system.

The loads are generally AC. However, battery banks, photovoltaic panels and sometimes wind-turbines deliver their energy in DC form. Therefore, a DC/AC converter (inverter) is required.

Fig. 1 shows a block-diagram of a generic hybrid-power generation system. The way energy flows is indicated by arrows.

Once the configuration of the hybrid-power system has been defined, the electric configuration must be established.

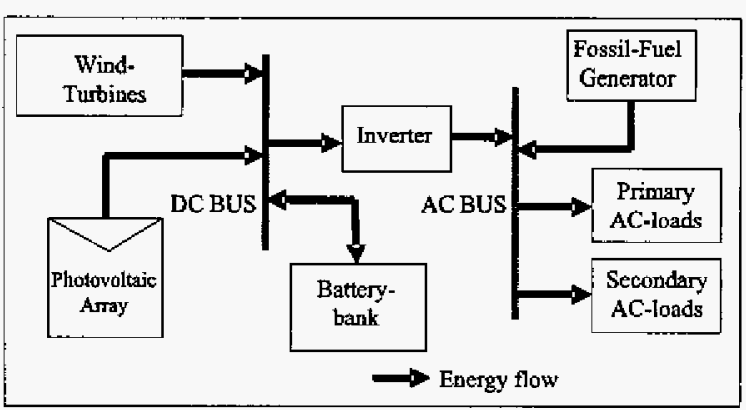

Fig. 1. Hybrid System Configuration.

I.e., how the system power sources must be interconnected, according to the type of electricity they deliver (DC or AC).

Photovoltaic arrays and the battery-bank are both connected to a DC-bus. Some small wind-turbines deliver a rectified DC output, therefore can also be connected to the DC bus. Since most of the loads require $A C$, an AC-bus is included. The outputs from the inverter and the fossil-fuelgenerator are connected to this bus.

Loads are classified as primary and secondary so that a better management of the system's energy can be achieved. Secondary loads can be disconnected from the system if the available energy is just enough to cover the primary loads' energy tequirements. If energy is plenty, secondary loads are supplied as well as the primary loads.

One of the main points to consider during the design of a hybrid system is sizing; i.e. select the nominal-power of every element in the system according to the power of the other elements.

In this paper, the nominal-power of every element matches the power of the corresponding element in a small hybrid system installed in Pachuca, Mexico.

The hybrid system in Pachuca has five $500 \mathrm{~W}$ windturbines "Avispa". This wind-turbine has a 3-blade, glassfiber, horizontal-axis rotor with a diameter of $1.8 \mathrm{~m}$. Its nominal-speed is $11.5 \mathrm{~m} / \mathrm{s}$, its start-speed is $3.5 \mathrm{~m} / \mathrm{s}$ and its exit-speed is $20 \mathrm{~m} / \mathrm{s}$.

The photovoltaic array is formed by thirty-six $75 \mathrm{~W}$, monocrystalline-silicon panels, divided into four $40 \mathrm{~m}^{2}, 9$-panel sub-arrays.

The battery bank is formed by six $2 \mathrm{~V}, 1500 \mathrm{~A}-\mathrm{hr}$, flatplate, lead-acid batteries designed for stationary applications and deep discharges. They are connected in series to obtain a total storage-capacity of $1500 \mathrm{~A}-\mathrm{hr} @ 12 \mathrm{VDC}$.

The systems also counts with a $2.5 \mathrm{KW}$ inverter/rectifier. The inverter, a U2512SB by Trace Engineering, has an efficiency between 85 and $96 \%$. It receives a DC input voltage between 10.8 and $15.6 \mathrm{~V}$, and delivers a $60 \mathrm{~Hz}, 120$ $\mathrm{VAC} \pm 2 \%$ sinusoidal voltage. 


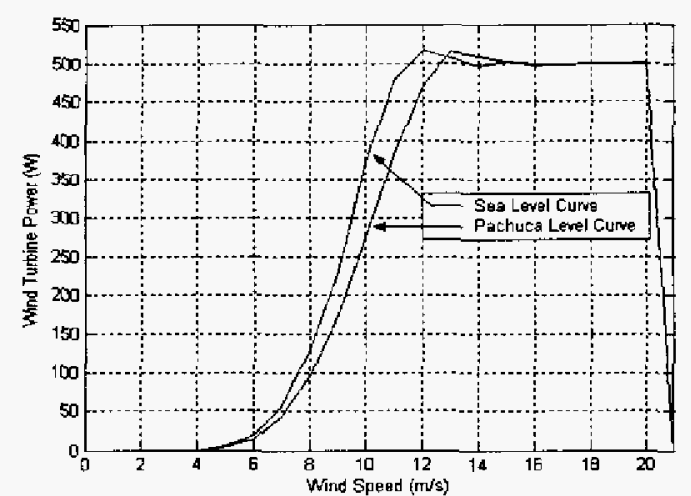

Fig. 2. "Avispa" Wind turbine power curves.

The fossil-fuel-generator has a nominal power of $6.5 \mathrm{KW}$ (a) 125 VAC.

\section{DESIGN AND VALIDATION OF THE MODELS}

\section{A.I Mathematical Model of Wind-Turbine}

Wind-turbines performance is generally presented in a Power vs. Wind-speed graph. Wind-speed is measured at the center of the rotor. Power-graphs for a particular windturbine are useful to estimate the energy it will provide under a given wind regime. Power-graphs for a particular wind-turbine model are experimentally obtained by means of controlled tests under free-wind conditions [1].

The equations that represent the power-graph of the witdturbine used in simulations are:

$$
P_{w}(v)=\left\{\begin{array}{cc}
0 & (v<4.3) \\
-0.2982 v^{4}+8.9963 v^{3}-88.001 v^{2}+359.2 v-530.03 \\
(4.3 \leq v<13.22) \\
-0.1521 v^{3}+8.48 v^{2}-156.46 v+1454.5 \\
(13.22 \leq v \leq 20) \\
0 \quad 20<v
\end{array}\right.
$$

Where $P_{w}(v)$ is the power at the wind-tutbine output, given wind-speed $v$ at the center of the rotor. Equations (1) are in the form proposed by [2]. Fig. 2 shows power-graphs of the wind-turbine "Avispa", one of them obtained at sea-level and the other adjusted to Pachuca hejght over sea-level.

\section{A.2 Experimental Validation of Wind-Turbine}

The wind-turbine's model was validated by comparing the power calculated by the power-graph versus the power measured at the output of an "Avispa" wind-turbine installed at Pachuca. The simulation model was fed with real windspeed data collected at 18 meters, the height at the center of the rotor. Fig. 3 shows the corresponding graphs.

In Fig. 3, the calculated power-graph is very close to the actual generated power. This proximity was achieved because the sea-level curve adjusted for Pachuca heightover-sea-level (Fig. 2) was used during simulations. The higher over-sea-level, the lower the power generated by wind-turbines.

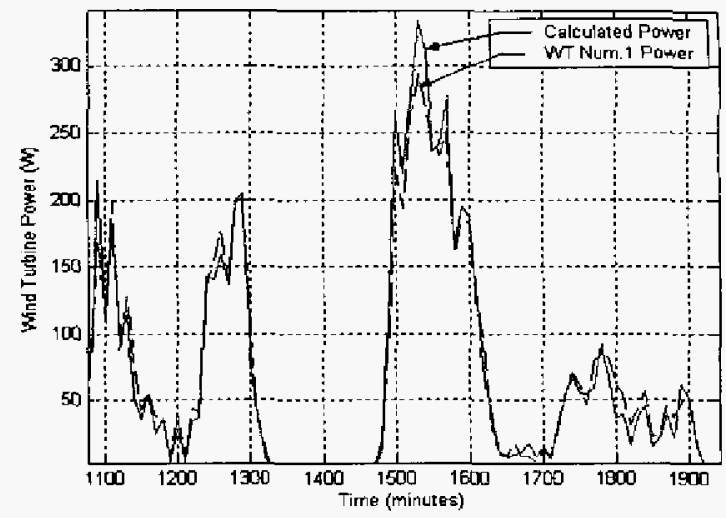

Fig, 3. Calculated and measured wind-turbine powers.

\section{B.I Mathematical Model of Photovoltaic Array}

Fig. 4 shows an equivalent circuit that can represent the behaviour of either an individual photovoltaic (PV) cell, or a panel made out of several PV-cells, or an array formed by several PV-panels.

The circuit in Fig. 4 requires five parameters to be known, namely: the light current $I_{L}$, the diode reverse saturation current $I_{D}$, the series resistance $R_{s}$, the shunt resistance $R_{s h}$ and the curve fitting parameter $a[3]$.

For constant solar radiation and temperature, the characteristic current_voltage (I-V) curve is given by (2), where $I$ and $V$ are the operational current and voltage, respectively:

$$
I=I_{L}-I_{D}\left\{\exp \left[\left(V+I R_{s}\right) / a\right]-1\right\}-\frac{V+I R_{s}}{R_{s h}}
$$

The power of the PV panel is given by:

$$
P=I V
$$

Fig. 5 shows the graph of equation (2), given a constant temperature and solar radiation. It also shows the graph power-voltage ( $P-V$ ) obtained from equation (3). The amount current a PV panel can generate mainly depends on two factors: solar radiation and temperature. The higher the solar radiation that hits the PV panel, the larger the current it generates.

In Fig. 5, the short-circuit current $I_{s c}$ is found in the $I-V$ curve where $V=0$; and the open-circuit voltage $V_{o c}$, is found in the same curve where $I=0$.

The maximum of the curve $P-V$ in Fig. 5 is the point of maximum power $P_{m p}$. At this point the current is $I_{m p}$ and voltage is $V_{m p}$. Ideally, a photovoltaic cell operates in the point of maximum power at all times. In practice however, the cell operates in a point of the $I-V$ curve that matches the $I-V$ curve of the load.

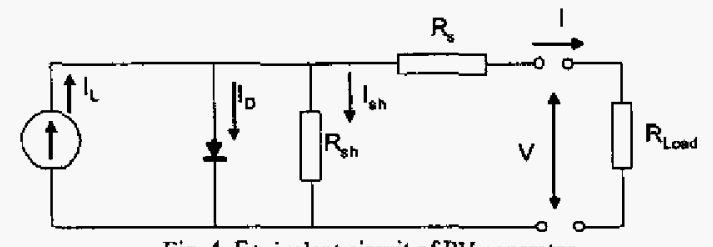

Fig, 4, Equivalent circuit of PV generater. 


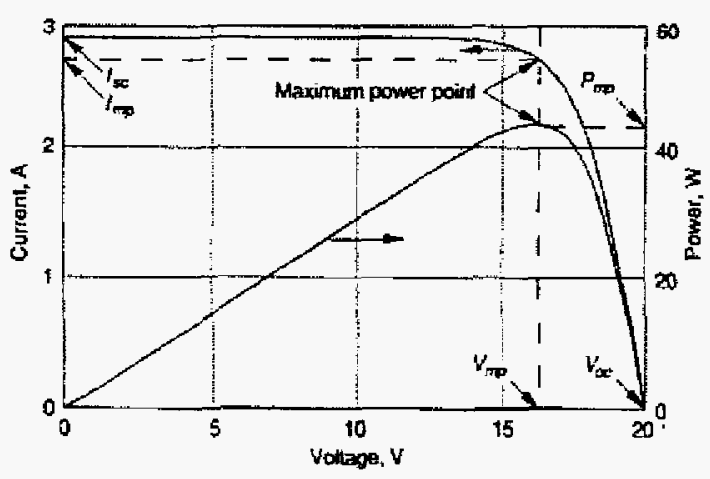

Fig. 5. Typical I-V and P-V performance curves for a PV Panel [3].

According to [4], when a PV array is connected to an $\mathrm{AC}$ bus via an inverter, the inverter acts as a tracker of the point of maximum power, therefore the PV array always operates in such point. Hence, the model for PV power needs to calculate $I_{m p}$ and $V_{m p}$ for a given temperature and solar radiation.

Alternatively, if the PV array is connected to a DC-bus, there is no tracking of the point of maximum power and therefore, the operational voltage of the PV array is the same as the voltage of the DC-bus. The curent corresponding to that voltage has to be found in the $I-V$ curve. Under these conditions, the PV array will operate outside the point of maximum power most of the time.

The hybrid system considered in this work presents the latter case. Therefore, the simulation model assumes that the PV array does not operate in the point of maximum power.

The expressions to calculate the parameters of equation (2) can be found in [3]. Using (2) and the calculated parameters, the current $I$ for a given DC-bus voltage $V$ can be found. Since equation (2) is implicit, the value of $l$ is obtained iteratively. Once $I$ and $V$ have been calculated for any given solar radiation and temperature, the power generated by the $\mathrm{PV}$ array under such conditions can be calculated with (3).

\section{B.2 Experimental Validation of Photovoltaic Array Model}

Fig. 6 shows the graphs for PV array power obtained with the model presented above.

Inputs for the model are: electric characteristics of the PV panels given by the manufacturer, solar radiation data collected at the same plane as the PV arrays, temperature in one of the PV panels and the battery-bank DC voltage.

The graphs in Fig. 6 show that the power calculated by the model is quite close to the power measured at the output of one panel in a sub-array. Differences are due to the fact that the model takes into account the voltage at the DC-bus and the measurements correspond to the voltage at the output of the battery-bank, which is smaller. Therefore, the power estimated by the model is acceptable for simulation purposes.

\section{C.1 Mathematical Model of Battery-Bank}

Several mathematical models for lead-acid batteries were studied. Some of these models are dynamic and others are static $[5,6]$. A model that estimates voltage and state-of- charge (SOC) during charge, discharge and gassing stages, is proposed in [7]. This model receives as inputs the $\mathrm{C}_{10}{ }^{3}$ parameter supplied by the manufachurer, the current received or delivered by the battery and the battery temperature.

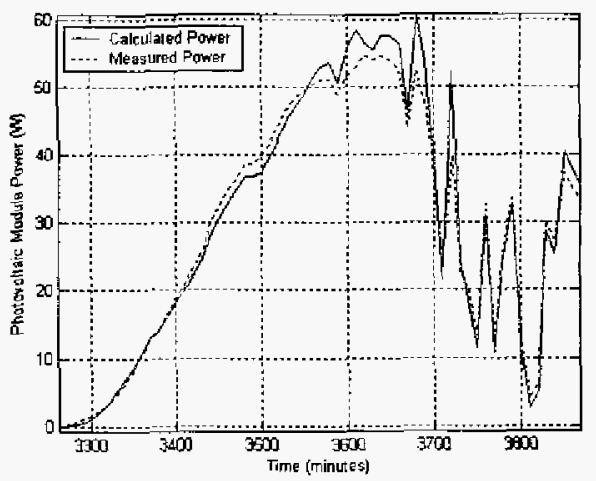

Fig. 6. Comparison of calculated power and measured power for the photovoltaic modules.

According to the model (for an individual 2V, lead-acid cell), the following equations describe the discharging process:

$$
\begin{gathered}
V_{d}=\left(2.085-0.12 \frac{Q}{C}\right)-\frac{I}{C_{10}}:\left(\frac{4}{1+I^{13}}+\frac{0.27}{\left(1-\frac{\left.Q / C_{T}\right)^{15}}{T}\right.}+0.02\right)(1-0.007 \Delta T) \\
C=\frac{C_{T}-\overline{1+0.9}}{1+0.67\left(\frac{I}{I_{10}}\right)^{0.9}} \\
C_{T}=1.67 C_{10}(1+0.005 \Delta T) \\
S O C_{2}=S O C_{\mathrm{t}}+\frac{Q}{C} \\
Q=I t
\end{gathered}
$$

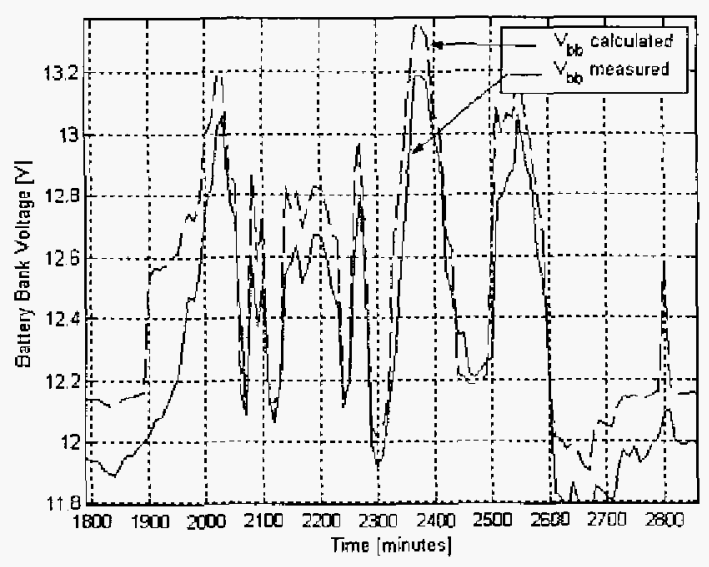

Fig. 7. Comparison of the battery hank calculated voltage and measured voltage (SOC $<80 \%$ ).

\footnotetext{
${ }^{1}$ Battery capacity in a 10-hour discharge-regime. I.e. capacity of the battery (in A-hr) for discharging from $100 \%$ to $0 \% \mathrm{SOC}$ in 10 hours, demanding a constant current. As the demanded curent grows, the capacity $C$ of the battery decreases.
} 
The charging process would be given by:

$$
\begin{gathered}
V_{e}=\left(2+0.16 \frac{Q}{C}\right)+\frac{I}{C_{10}}\left(\frac{6}{1+I^{0.5}}+\frac{0.48}{\left(1-\frac{Q}{C_{\mathrm{r}}}\right)^{12}}+0.036\right)(1-0.025 \Delta T) \\
S O C_{2}=S O C_{1}+\frac{Q}{C} \eta_{c} \\
\left.\eta_{c}=1-e^{-\frac{20.73}{\frac{I}{19}_{10.55}}(S O C-1)}\right]
\end{gathered}
$$

For the over-charging process (when $\mathrm{V} \leq \mathrm{Vg}$ ), the following equations are proposed:

$$
\begin{gathered}
V_{\text {ec }}=\left(2.45+2.011 \ln \left(1+\frac{I}{C_{10}}\right)(1-0.002 \Delta T)\right. \\
V_{g}=\left(2.24+1.97 \ln \left(1+\frac{I}{C_{10}}\right)(1-0.002 \Delta T)\right. \\
V=V_{g}+\left(V_{\text {et }}-V_{g}\right)\left(1-e^{\left(\frac{Q-0.95 C}{I t}\right)}\right) \\
t=\frac{17.3}{1+852\left(\frac{I}{C_{10}}\right)^{1.0 T}}
\end{gathered}
$$

C Battery capacity.

$\mathrm{C}_{10} \quad$ Battery's capacity at the nominal $10 \mathrm{~h}$ discharge rate.

$\Delta \mathrm{T}$ Increment of temperature. Taking as reference $25^{\circ} \mathrm{C}$.

I Battery current, positive during charge and negative during discharge.

$V_{c} \quad$ Battery voltage during the charge.

$V_{d} \quad$ Battery voltage during the discharge.

$V_{\mathrm{cr}} \quad$ Equalization voltage.

$V_{B} \quad$ Battery voltage of the gasification.

$\eta_{c} \quad$ Charge battery efficiency.

$\mathrm{I}_{10} \quad$ Battery current at $\mathrm{C}_{10}$.

Q Charge delivered or supplied at time of interest.

$\mathrm{C}_{\mathrm{T}}$ Maximum capacity of the battery.

$t$ Time of interest.

$\mathrm{SOC}_{1}$ State of charge at state 1.

$\mathrm{SOC}_{2}$ State of charge at state 2 .

\section{C.2 Experimental Validation of Battery Bank}

Validation of the selected model was carried out by comparing the model response against the hybrid system voltage measured at Pachuca. Preliminary results showed that the model accurately estimated the battery-bank voltage for medium and low SOC conditions (Fig. 7). However, for SOC near $100 \%$, the model did not perform so well (Fig. 8).

The model was adjusted for bigh SOC conditions (SOC near $100 \%$ ), by calculating the battery-bank voltage using equation (13). This is valid assuming that the voltage for $85 \%$ SOC is $13.8 \mathrm{~V}$ and that at $13.8 \mathrm{~V}$ the battery starts to gasify.

Hence, the model estimates the battery-bank voltage using eq. (4) during discharging, eq. (9) during charging and eq. (13) when the voltage is higher than $13.8 \mathrm{~V}$.

A further adjustment was performed on the model for the condition when voltage is lower than $13.8 \mathrm{~V}$ but the SOC is higher than $95 \%$. Under these conditions, the model uses equation (13) to estimate the battery-bank voltage.

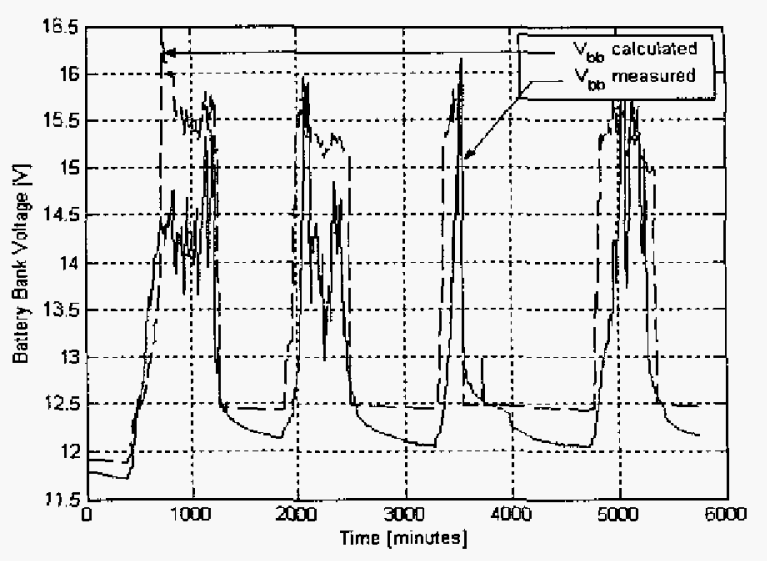

Fig. 8. Comparison of the battery bank calculated voltage and measured voltage (SOC near to $100 \%$ ).

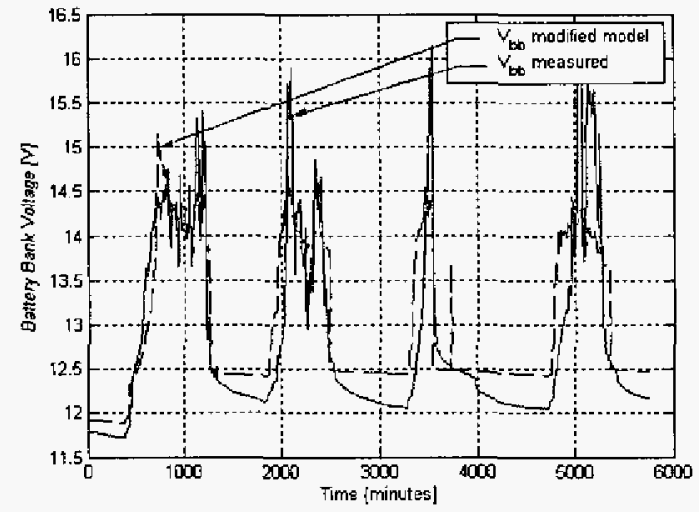

Fig. 9. Comparison of the battery bank voltage: output of the modified model and the data measured ( $S O C$ near to $100 \%$ ).

Fig. 9 shows the battery-bank voltage estimated using the model proposed in [7], the modified model described above and actual measured voltage. It noticeable that the voltage estimated using the modified model is closer to the real values than the voltage estimated with the original model.

The main difference between the two models is the accuracy at SOC near $100 \%$. For medium and low SOC, the model in [7] estimates the voltage accurately (Fig. 7).

For control purposes, on-line estimation of battery-bank $\mathrm{SOC}$ is very important; this parameter provides an indication of how all the generating and consuming elements in the system are operating.

Fig. 10 shows the graphs of the battery-bank SOC estirnated using the model in [7] and the model proposed in [8]. It is noticeable that both graphs are very similar to each other.

\section{Mathematical Model of Power Converter}

According to [4], the power delivered by an inverter is given by:

$$
\begin{gathered}
P_{\text {our }}=\left(P_{\text {in }}-P_{N L}\right) / B_{\text {out }} \\
B_{\text {out }}=\left(P_{R} / \eta_{R}-P_{N L}\right) / P_{R}
\end{gathered}
$$




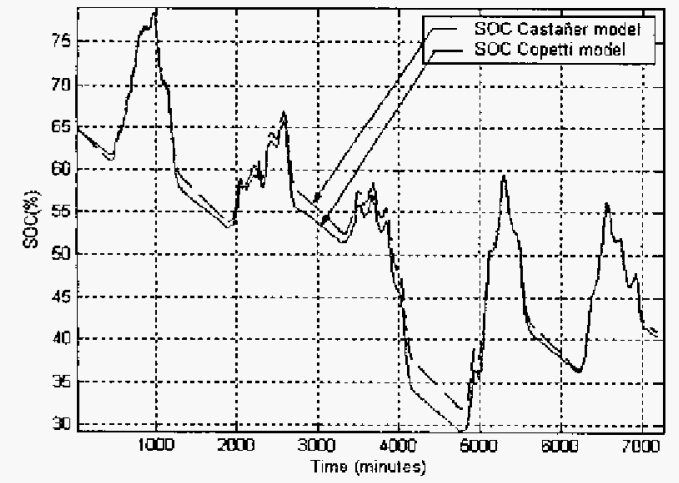

Fig. 10. Comparison between two SOC models, Copetti model [7] and Castan̂ter model [8]

where,

$P_{\text {our }} \quad$ Output power, $\mathrm{kW}$

$P_{\text {in }} \quad$ Input power, $\mathrm{kW}$

$P_{N L} \quad$ No load power, $\mathrm{kW}$

$B_{\text {out }} \quad$ Constant relating input power to output powet

$P_{R} \quad$ Rated output power, $\mathrm{kW}$

$\eta_{R} \quad$ Rated efficiency

The hybrid system operates under the assumption that it provides all the power demanded by a given load $\left(P_{\text {out }}\right)$, and therefore the unknown parameter in (16) is $P_{i n}$. The power required by the inverter in order to fully supply the power demanded by the load is:

$$
P_{\text {in }}=P_{\text {out }} B_{\text {out }}+P_{N L}
$$

The efficiency of the inverter installed in Pachuca is given by a curve provided by the manufacturer, its value is between 85 and $96 \%$. An equation to estimate efficiency as a function of power was derived from the efficiency curve. This equation is used by the simulator to estimate the inverter's efficiency for a given instant-power demanded by the load.

\section{E. Mathematical Model of Electric Loads}

To simulate the loads of the hybrid system, measured patterns of the power demanded by two food-manufacturing processes (meat and dairy products), were used. Figs. 11 and 12 show the corresponding graphs.

The food-manufacturing processes were selected because their demand-patterns are periodic, i.e. they demand similat amounts of energy during approximately the same time, every day. Therefore, by repeating the demand-patterns of one day, it is possible to simulate the behaviour of the hybrid system for any number of days. For simulation, the demandpattern of the meat-products process was considered as the primary load; whereas the demand-pattern of the dairyproducts process was used as the secondary load.

\section{F. Mathematical Model of the Internal-Combustion Machine}

The mathematical models representing the operation of an internal-combustion machine usually provide the output power as a function of fuel consumption [9].

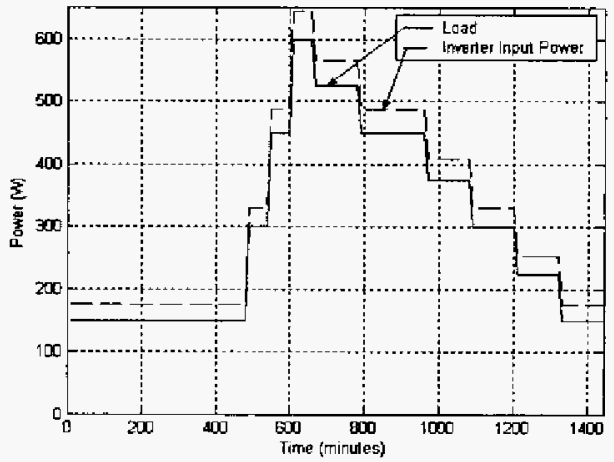

Fig. 11. Demand-pattern of primary load (meat process) and inverter input power.

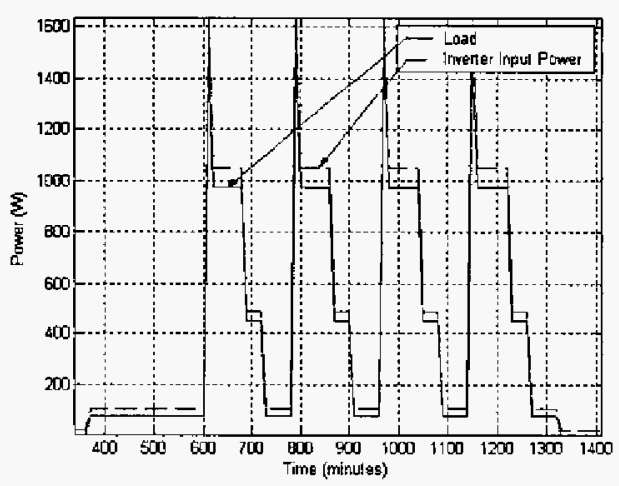

Fig. 12. Demand-pattern of secondary load (dairy process) and inverter input power.

Fossil-fuel generators (diesel, gasoline, etc.) supply energy in one of two ways. Either they generate only the power needed by the load (load tracking), or they generate at nominal power and the surplus energy (if any), is used to charge the battery-bank. In this work, a fossil-fuel generator of the first kind was considered. The charging of the batterybank is left to the renewable-energy sources.

The fossil-fuel generator model is represented by a curve showing fuel consumed versus output power. The fossil-fuel generator provides the energy needed to complete the load's power requirements beyond the renewable-energy generators' capacity.

\section{COMMENTS ABOUT THE MODELS}

The main objective of this work was the analysis and design of the models validated in the previous section. Good dynamic response of wind-turbine, photovoltaic array and battery models have been obtained and acceptable comparision with experimental results have been done. However, significant model limitations can be considered and highlight in this section.

In this respect, for the wind-turbine model, a good dynamic response is obtained if an adjusted height-over-sealevel power curve is used (Fig. 2), and wind speed is actually collected at the height of the center of the rotor.

Regarding the photovoltaic array, it is necessary the measurement of the voltage of the bus to which the array is connected to. However, this measurement is very difficult to obtain, so it is common to use the measurement of the 
battery voltage instead of the bus voltage. This fact should introduce errors in the validation process and must be taken into account.

Battery bark model has been considerably improved in this work with the inclusion of the correction for SOC values near $100 \%$. In addition, the most important contribution to the battery model is the obtention of the online SOC that penmits further suitable implementation of the supervisory controller [7].

Stationary models of the power converter and the internal combustión machine are simple but enough to determine the dynamic response of the whole system.

Finally, electric load model responds to especific foodmanufacturing proceses where the load distribution for each day is constant, but it is possible to adapt it to smaller or bigher demand.

\section{PROGRAM SIMULATION}

Section III presented the models used to simulate the behavior of a hybrid, power-generation system and their individual validation. In order to simulate the interaction between components, a simulation program that includes all the models was developed. Figure 13 shows the results obtained after simulating four days of operation. The total power generated by the wind-turbines and photovoltaic modules are shown along with the total power demanded by the dairy-products manufacturing process.

The battery-bank's SOC has to be estimated on-line from its initial state using the power demanded and generated in the system. As mentioned, SOC is the main parameter in the decision-making process of an intelligent controller. Fig. 14 shows the behavior of the battery-bank's state-of-charge. It shows how the SOC grows when the energy generated is bigget than the energy demanded by the load. Conversely, the SOC decreases when the battery-bank has to provide energy to the load.

Different generation-and-demand scenarios can be tested using the simulation tool presented in this paper. Different control algorithms can also be validated and tuned in order to achieve optimum operation of a hybrid system. Hybridgeneration processes that take days or weeks to develop during normal operation can be simulated in minutes using the tool described in this paper.

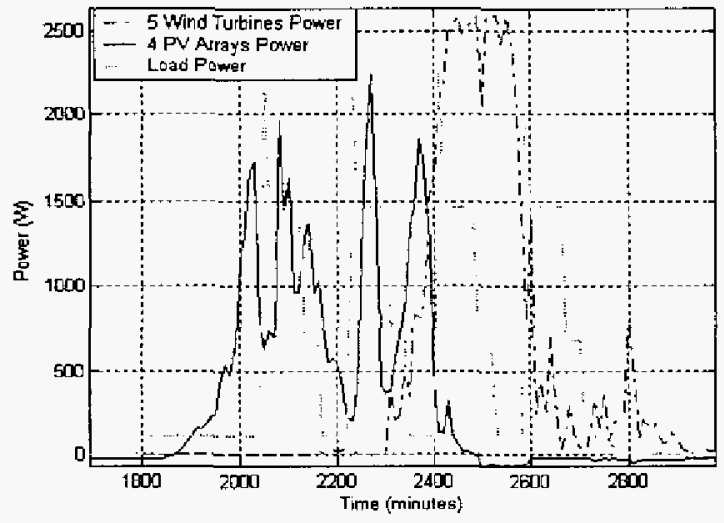

Fig. 13. Response of the wind turbines, PV-amays and load.

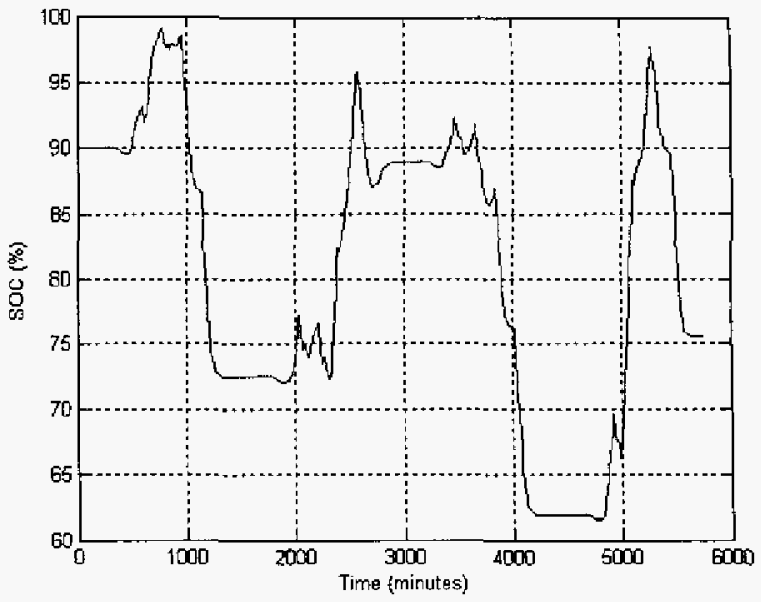

Fig. 14. SOC of the battery-bank during 4 days of simulation.

\section{CONCLUSIONS}

This paper presented a simulation tool of hybrid systems consisting of wind-turbines, PV-modules, battery-bank and fossil-fuel power generator.

The models proposed in the literature have been validated against measurements obtained in an experimental hybrid system. This validation supports the reliability of the simulation tool.

A model for the battery-bank proposed in the literature was modified in order to improve its response when the battery's SOC is near $100 \%$. The output of the modified SOC model was validated by comparing it with the output of the model proposed in [8]. Both models delivered similar results.

The tool has been used to test the performance of different control algorithms.

\section{REFERENCES}

[1] M. Borja, et al; "Estado del arte y tendencias de la tecnologia eoloeléctrica"; Programa Universitario de Energia; Coordinación de vinculación; UNAM; 1998.

[2] B. Ai et al; Computer-aided design of PV/wind hybrid system; Renewable Energy 28; pp 1491-1512; Elsevier; 2003.

[3] J. Duffie and W. Beckman, Solar Engineering Of Thermal Processes, Ed. Wiley; New York; 1991.

[4] J. F. Manwell; et al; Hybrid2 - A Hybrid System Simulation Model Theory Manual; November 1998; University of Massachusetts-National Renewable Energy Laboratory.

[5] Ceraolo Massimo; "New dynamical models of lead-acid batteries"; IEEE Transactions on Power Systems; Vol. 15; No. 4; Noviembre, 2000.

[6] M. Ross, "A simple but comprehensive lead acid battery model for hybrid system simulation"; in Workshop on photovollaic Hybrid System; Montreal, Canada, 2001.

[7] J. Copetti, F. Chenlo, "Lead/acid batteries for photovoltaic applications. Test restits and modelling"; Jounal of Power Sources; 1994; pp 109-118.

[8] L. Castaiter and S. Silvestre, Modelling photovoltaic systems using PSpice; Ed. Wiley; 2002.

[9] A. Lemos de Pereita, Modular stpervisory controller for hybrid systems; PhD Thesis; RISD National Laboratory, Roskilde, Denmark; June 2000. 